\title{
Practical Principles of Lean Management in Ukraine
}

\author{
Viktoriia Yevtushenko [0000-0002-7764-2277], Marina Kudinova [0000-0002-7163-2721]*, \\ Viktoriia Liashevska [0000-0001-6520-3632] \\ V.N. Karazin Kharkiv national University, Kharkiv, Ukraine \\ *kudinova@karazin.ua
}

\begin{abstract}
The purpose of the study is to summarize the applied experience of lean management in Ukrainian companies and compare it with the practices of foreign companies. The objects of the study were such companies as Starbucks (USA), Nike (USA), Philips (Netherlands), Volvo Cars (Sweden), Nova Poshta (Ukraine), Alfa-Bank (Ukraine), Kyivstar (Ukraine), MHP (Ukraine). The author analyzes the advantages of lean management, its impact on profitability, productivity, quality, operational processes, compared with the results of lean implementation in Ukraine. The systematized modern practices of lean management are the model "a deep-dive experience", an Obeya room and leanleadership. The principles of lean in Ukrainian business have been analyzed, it has been determined that in general the management is focused on optimization of operational processes, automation of production, efficient organization of workspaces. Attention is drawn to the fact that in domestic companies, lean management hasn't covered the entire organization, hasn't become its philosophy, hasn't determined the strategy of its development, but is rather periodic and fragmentary so far. The results of the study prove that in general Ukrainian organizations are moving in the right direction, based on their capabilities, the feasibility of developing an adapted algorithm for implementing lean management not only in large business but also in medium and small business.
\end{abstract}

Keywords: lean management, organizational philosophy, Lean Institute Ukraine, cost minimization / elimination, continuous improvement.

\section{INTRODUCTION}

Currently Ukrainian business is actively transforming, increasing its competitiveness in world markets and creating a new internal institutional environment that encourages all domestic companies to change more dynamically in accordance with market requirements. Lean-management is the organizational philosophy that will allow the company to improve quality, be more flexible and economical and adapt more quickly to new trends [1].

Lean-production originates in Japan, and its effectiveness has spread almost all over the world. With increasing frequency, organizations use lean tools to optimize their operational processes and improve overall management regardless of their country of origin, their activity, their size $[2,3]$.

Aspects of lean-management are also studied in academic circles, not only in terms of practical business implementation, but also as effective methods of managing educational institutions and improving service delivery processes [4-8].
Analysis of the references shows that in Ukraine not much research on this topic has been done in recent years [9-15].

Lean-management has received practical development in Ukraine thanks to the efforts of Lean Institute Ukraine, which is a representative of the global network «Lean Global Network». The best stimulus for the lean-principles introduction in the organization activities is illustrative examples of the lean-management usage in specific foreign and Ukrainian companies, the generalization and comparison of practices which this study is devoted to.

\section{RESEARCH METHODOLOGY}

The work is based on the analysis of periodical literature, materials of Lean Institute Ukraine and its educational programmes and online courses on the usage of Lean-methodology [16], materials of the Prometheus course "Introduction to Lean" [17], open data of foreign and Ukrainian companies on the implementation and use of lean-management (Starbucks (USA), Nike (USA), Philips (Netherlands), Volvo Cars (Sweden), Nova 
Poshta (Ukraine), Alfa-Bank (Ukraine), Kyivstar (Ukraine), MHP (Ukraine). In these companies a qualitative study of the Lean tools usage has been undertaken, their usage bottlenecks have been identified, much of the attention has been focused on the inconsistency of Lean-implementation in Ukrainian business, all the studied practices are selective, do not cover the entire organization, which reduces the Leaneffect.

\section{RESULTS OF THE RESEARCH}

The need to introduce lean-management in organizational processes and its effectiveness has long been beyond doubt, among the adherents of this concept such world-famous companies as Google, Amazon, Tesla, Ford, IKEA, Starbucks, Apple and many others can be found. Optimization of operational processes, automation, reduction of shortages and the goods and services quality improvement, a corporate culture element - all this has long been a hallmark of leanmanagement (Figure 1).

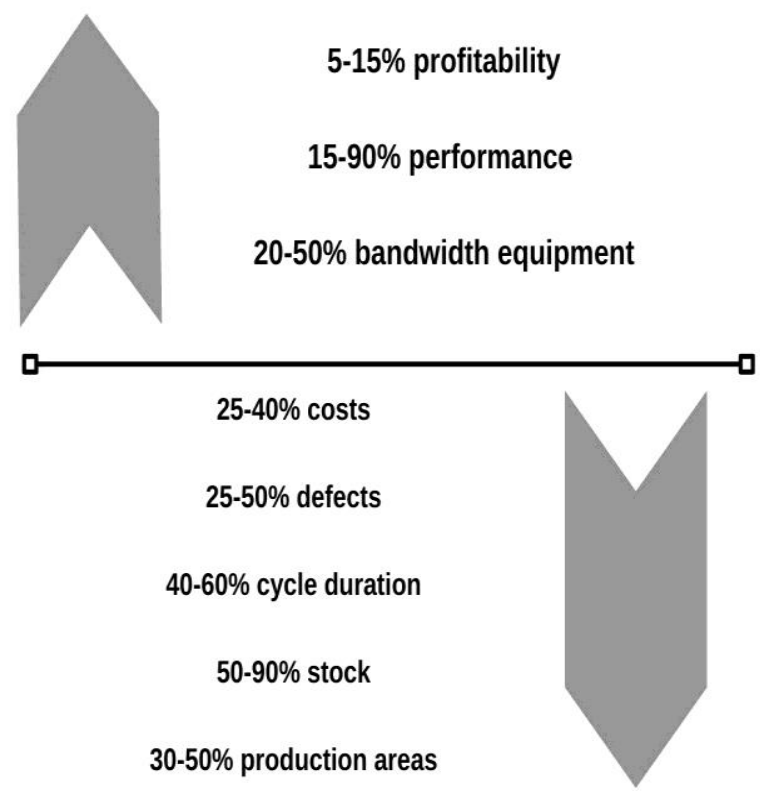

Figure 1 Advantages of lean-management [18]

We've summarized the effective practices of some international companies to better understand the benefits and bottlenecks that arise when implementing the leanconcept. Starbucks has created a unique deep-dive leadership model (developed by Scott Haydon and Josh Howell) [19].

Its advantages are the systematic accumulation and transfer of practical knowledge and skills, the mentoring development. Each manager directly "immerses" in work processes (for example, makes coffee, serves customers, makes orders, etc.) to understand all operational aspects. This experience allows you then to transfer this knowledge to the direct performers, adapt them quickly to new conditions and continuous learning (i.e. teaching one, we teach all). The problem areas of this approach include the following: attempts to simplify and automate all processes in the organization, which is not possible. Nike is one of the most innovative corporations in the world. It implemented the basic principles of lean through the visualization of management processes and decision-making [20-22] tool "An obeya room" [23]. The usage of these lean tools has contributed to the creation of a separate space, filled with certain visual content and tools, that is aimed at solving a specific task. The team is immersed in a specific issue, nothing distracts it from solving it. The efficiency of decision-making, implementation of new ideas is growing rapidly. At the same time, there is a slow implementation of control and formal procedures, without which it is difficult to understand whether you have achieved your goal so far. Philips has been involved in lean-transformation for many years, the main focus of which is the formation of effective line leaders and "continuous improvement" [24]. Lean-transformation coaches teach and practice the lean tools usage among the company's management, regardless of the country of the representative office or the level of management. Teamwork, shared responsibility for results, practical skills and continuous improvement accompany this process. The bottlenecks of this approach include trainings do not fully model the conditions of the real operational process. Transferring lean-skills to employees who do not understand it at all is a slow process. Volvo Cars focuses on improving production processes and training leaders who can pass on the necessary practical knowledge to their subordinates [25]. The implementation effectiveness of lean-management is to bring all operational processes to the maximum possible "perfect" state, automation and implementation of the principles of Kaizen. Involvement of employees in the improvement of the production process, increasing their independence in action, increasing responsibility and effective teamwork. Certain disadvantages of this approach include the following: the organization does not end only in production and automation, there are other components that require timely intervention and implementation of lean management. In general, the analyzed examples are quite typical for other companies and fully comply with the basic principles of TPS automation, visualization, teamwork, clear planning and organization, thorough process study. In Ukraine, leanmanagement is also used to improve the activities of such companies as Alfa-Bank, Nova Poshta, Kyivstar, Biopharma, MHP and others [16; 26]. In general, these are big business representatives who can afford such transformations. Let's compare what tools and elements of lean-management are used by domestic companies. According to the Lean Institute Ukraine, national companies, that are actively implementing this concept in their activities, were able to obtain the following results (Figure 2). 


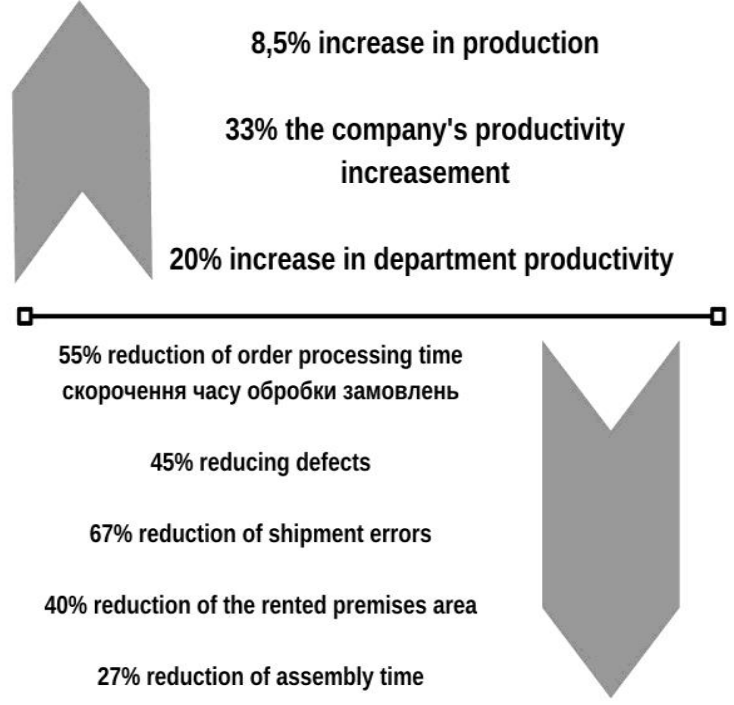

Figure 2 The effectiveness of lean-management in Ukrainian companies [16]

The Lean-team of Nova Poshta has been operating for over 1.5 years. During this time we managed to save space by $20 \%$, speed up the search for a parcel by $43 \%$, increase the productivity of the department by $20 \%$, decrease the number of queues. The main focus of the team's work is a systematic analysis of the workspace and its optimization, reduction of unnecessary actions of service staff, finding ways to increase the speed of service. The company tries to eliminate from its activities unnecessary "costs" that do not build value either for customers or for the organization itself. MHP entrepreneurship focused its efforts in leantransformation on the optimization of operational processes, which allowed to increase production by $8.6 \%$ per day and increase the efficiency of packaging equipment from 85 to $93 \%$. Alfa-Bank has focused on improving the workplace and staff space of the branch, leaving only the necessary equipment for the necessary facilities. The company is also currently working on the workflow optimizing and increasing the speed of providing certain services. Kyivstar implements the Lean concept in the field of project management, creating cross-functional teams and using Kanban tools.

\section{DISCUSSION OF RESULTS}

The generalization of lean-management practices of Ukrainian companies shows a clear tendency to optimize only production processes or service delivery processes. And a partial focus on staff training and preparation for the basic use of Lean tools (minimizing and eliminating losses, optimizing the workplace or space, etc.). In general, Lean-processes do not cover the entire management system of the organization, but rather are sporadic, aimed at achieving short-term goals. Figure 3 presents the results of a qualitative analysis of the Leanprinciples implementation in the activities of Ukrainian and foreign companies, which fully confirms our findings.
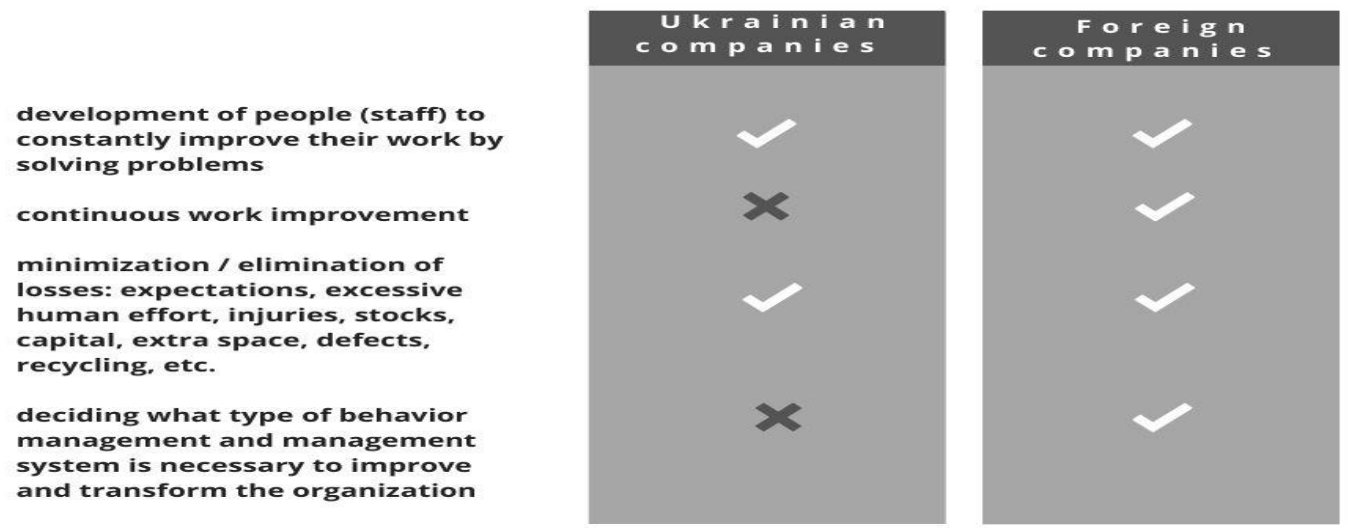

Figure 3 Results of a qualitative study of lean-management practices of Ukrainian and foreign companies

In Ukrainian business, there is still no perception of Lean as a company philosophy that affects absolutely all areas of its life. Therefore, the role of such organizations as Lean Institute Ukraine, which promote this concept among domestic organizations, is currently growing. In the future their number will only grow. The business itself, having received positive results from the implementation of this practice, will be actively involved and cooperate with international organizations and partners for the development of Lean-practices. The practical result of the study is to generalize the domestic experience of using the lean-management principles, comparing it with foreign practices, focusing on those principles that need to be developed in Ukrainian companies. In the future, it is advisable to develop Leanpractices adapted to the national characteristics and 
develop an algorithm for their implementation not only in large businesses, but also medium and small enterprises.

\section{CONCLUSIONS}

In general, Ukraine, despite the relatively small experience of lean-management compared to other countries, still has some positive results:

- big business, which is the flagship of the Ukrainian economy and an example for other companies, actively uses lean in its activities, albeit the fragmentary nature;

- optimization of operational processes, workspace and production areas give tangible results that satisfy customers of companies, their staff, other stakeholders;

- lean is gradually becoming an element of the company's corporate culture, which will become its philosophy in the future;

- The emergence of organizations such as Lean Institute Ukraine promotes and disseminates the practice of lean-management in Ukraine.

\section{REFERENCES}

[1] Sinha, N. and Matharu, M. (2019), "A Comprehensive Insight into Lean Management: Literature Review and Trends", Journal of Industrial Engineering and Management, vol. 12(2), pp. 302-317, DOI:10.3926/jiem.2885

[2] Chaplin, L. Heap, J. and O'Rourke, S.T. (2016), "Could "Lean Lite" be the cost effective solution to applying lean manufacturing in developing economies?", International Journal of Productivity and Performance Management, vol. 65 (1), pp. 126-136, DOI:10.1108/IJPPM-02-2015-0034

[3] Khalil, Al-Hyari (2020), "Lean bundles within Jordanian manufacturing SMEs and their effect on business performance", Problems and Perspectives in Management, vol. 18, iss. 2, pp. 302-315, DOI:10.21511/ppm.18(2).2020.25

[4] Abolhassani, A. Layfield, K. and Gopalakrishnan, B. (2016), "Lean and US manufacturing industry: popularity of practices and implementation barriers", International Journal of Productivity and Performance Management, vol. 65(7), pp. 875-897, DOI: 10.1108/IJPPM-102014-0157

[5] Gao, T. and Gurd, B. (2019), “Organizational issues for the lean success in China: exploring a change strategy for lean success", BMC health services research, vol. 19(1), pp. 66, DOI: 10.1186/s12913-019-3907-6
[6] Hallam, C. and Contreras, C. (2016), "Integrating lean and green management", Management Decision, vol. 54 (9), pp. 2157-2187, DOI: 10.1108/MD-04-2016-0259

[7] Langstrand, J. and Drotz, E. (2016), "The rhetoric and reality of Lean: a multiple case study", Total Quality Management \& Business Excellence, vol. 27(3-4), pp. 398-412, DOI: $10.1080 / 14783363.2015 .1004307$

[8] Laureani, A. and Antony, J. (2019), "Leadership and Lean Six Sigma: a systematic literature review", Total Quality Management \& Business Excellence, vol. 30 (1-2), pp. 53-81, DOI: $10.1080 / 14783363.2017 .1288565$

[9] Kolos, I. (2018), "Diagnostics in lean management system of industrial enterprise", Technology audit and production reserves, vol. 2(4), pp. 19-23.

[10] Bek, O. and Petecki, I. (2017), "Lean-management as an innovative approach to production management", Journal of Lviv Polytechnic National University, vol. 863, pp. 12-16.

[11] Madgerova, R.H. Kyurova, V.V. and Atanasova, A.V. (2016), "Application of the lean concept as a prerequisite for a tourist business development", Economic Processes Management, vol. 4, available at: http://nbuv.gov.ua/UJRN/EPM_2016_4_17

[12] Kotlyarevsky, Ya.V. Radchenko, A.I. Melnikov, O.V. and Semenyuk, E.P. (2018), "Strategic Priorities in Measuring the Publication and Publishing Works in Scholarly Research Activity", Sci. Innov., vol. 14, no. 5, pp. 5-16.

[13] Kotlyarevsky, Ya.V. Melnikov, O.V. Kniaziev, S.I. Shtangret, A.M. and Semenyuk, E.P. (2019), "Methodological Approaches to Labor Norming in Scholarly Research and Development", Sci. Innov., vol. 15, no. 1, pp. 5-24, DOI: $10.15407 /$ scine15.01.005.

[14] Tkachenko, Volodymyr Kwilinski, Aleksy Korystin, Oleksandr Svyrydiuk, Natalia and Tkachenko, Iryna (2019), “Assessment of information technologies influence on financial security of economy", Journal of security and sustainability issues, march, vol. 8, no. 3, pp. 375385, DOI: $10.9770 /$ jssi.2019.8.3(7)

[15] Korystin, O.Ye. (2020), Chapter 4. State Legal Police of Scientific Prediction. Public administration in the digital economy, monograph, Tallinn, Scientific Center of Innovative Researches OU, DOI: 10.36690 PADE 
[16] Lean Institute Ukraine, available at: https://lean.org.ua

[17] Introduction to Lean. Prometheus, available at: https://courses.prometheus.org.ua/courses/coursev1:Prometheus+Lean101+2021_T1/about

[18] Lean Six Sigma is a combination of methodologies for the best result (2017, September 25), available at: https://worksection.com/blog/lean-sixsigma.html

[19] Gaudet, K. (2019), The Sunday-night barista, April 30, available at: https://planet-lean.com/spreadinglean-thinking-starbucks

[20] Cigdem Tarhan and Can Aydın (2019), "Why Should Municipalities Use Management Information Systems in Their Decision-Making Processes?", International Journal of Information Technology and Computer Science, vol. 11, no. 4, pp.1-8, DOI: 10.5815/ijitcs.2019.04.01

[21] Tengku Adil Tengku Izhar (2017), “Ontology Based Framework to Configure the Organizational Goal Analysis and Decision-Making”, International Journal of Information Technology and Computer
Science, vol. 9, no. 9, pp. 53-59, DOI: $10.5815 /$ ijitcs.2017.09.05

[22] Darshan, M. Tank (2015), "Enable Better and Timelier Decision-Making Using Real-Time Business Intelligence System", IJIEEB, vol. 7, no. 1, pp.43-48, DOI: 10.5815/ijieeb.2015.01.06

[23] Mathijssen, F. (2014), How Nike created a successful lean IT obeya, December 11, available at: https://planet-lean.com/lean-management-nikeobeya/

[24] Lum, C. and Danielsen, J.B. (2019), Truly leading a transformation, May 14, available at: https://planet-lean.com/lean-leadershipdevelopment-philips/

[25] Reke, E. and Frick, G. (2019). Leadership development at Volvo Cars, September 16, available at: https://planet-lean.com/leanleadership-volvo-cars/

[26] Pokatys, V. (2019), How Ukrainian business applies Toyota's lean manufacturing philosophy, May 22, available at: https://delo.ua/business/kakukrainskij-biznes-primenjaet-filosofiju-toyo353488/ 